\title{
Docosahexaenoic acid-containing choline phospholipid modulates LPS-induced neuroinflammation in vivo and in microglia in vitro
}

Célia Fourrier ${ }^{1,2}$, Julie Remus-Borel ${ }^{1,2}$, Andrew D. Greenhalgh ${ }^{1,2}$, Michel Guichardant ${ }^{3}$, Nathalie Bernoud-Hubac ${ }^{3}$, Michel Lagarde ${ }^{3}$, Corinne Joffre ${ }^{1,2^{*}}$ and Sophie Layé ${ }^{1,2^{*}}$ (i)

\begin{abstract}
Background: Neuroinflammatory processes are considered a double-edged sword, having both protective and detrimental effects in the brain. Microglia, the brain's resident innate immune cells, are a key component of neuroinflammatory response. There is a growing interest in developing drugs to target microglia and control neuroinflammatory processes. In this regard, docosahexaenoic acid (DHA), the brain's n-3 polyunsaturated fatty acid, is a promising molecule to regulate pro-inflammatory microglia and cytokine production. Several works reported that the bioavailability of DHA to the brain is higher when DHA is acylated to phospholipid. In this work, we analyzed the antiinflammatory activity of DHA-phospholipid, either acetylated at the sn-1 position (AceDoPC, a stable form thought to have superior access to the brain) or acylated with palmitic acid at the sn-1 position (PC-DHA) using a lipopolysaccharide (LPS)-induced neuroinflammation model both in vitro and in vivo.
\end{abstract}

Methods: In vivo, adult C57Bl6/J mice were injected intravenously (i.v.) with either AceDoPC or PC-DHA $24 \mathrm{~h}$ prior to LPS (i.p.). For in vitro studies, immortalized murine microglia cells BV-2 were co-incubated with DHA forms and LPS. AceDoPC and PC-DHA effect on brain or BV-2 PUFA content was assessed by gas chromatography. LPS-induced pro-inflammatory cytokines interleukin IL-1 $\beta, I L-6$, and tumor necrosis factor (TNF) a production were measured by quantitative PCR (qPCR) or multiplex. IL-6 receptors and associated signaling pathway STAT3 were assessed by FACS analysis and western-blot in vitro.

Results: In vivo, a single injection of AceDoPC or PC-DHA decreased LPS-induced IL-6 production in the hippocampus of mice. This effect could be linked to their direct effect on microglia, as revealed in vitro. In addition, AceDoPC or PCDHA reduced IL-6 receptor while only AceDoPC decreased IL-6-induced STAT3 phosphorylation.

Conclusions: These results highlight the potency of administered DHA-acetylated to phospholipids—to rapidly regulate LPS-induced neuroinflammatory processes through their effect on microglia. In particular, both IL-6 production and signaling are targeted by AceDoPC in microglia.

Keywords: DHA, AceDoPC, Microglia, IL-6, STAT3, Intravenous, TNFa, IL-1 $\beta$, Phospholipid, PC-DHA

\footnotetext{
*Correspondence: corinne.joffre@inra.fr; sophie.laye@inra.fr

'INRA, Nutrition et Neurobiologie Intégrée, UMR 1286, 33076 Bordeaux,

France

Full list of author information is available at the end of the article
} 


\section{Background}

Docosahexaenoic acid (DHA) is a prominent long chain omega-3 polyunsaturated fatty acid (LC PUFA) of the brain, where it regulates both the structure and function of neurons, glia, and endothelial cells [1]. This PUFA also exerts protective activity against inflammation in the brain. Indeed, using a combination of dietary and transgenic mice models, we and others have demonstrated that increased brain DHA attenuates neuroinflammatory processes, while decreased brain DHA promotes them [2-10]. DHA's role in neuroinflammation is likely due to its direct effect on microglia, the resident innate immune cells of the brain, and its oxygenasederived metabolites (neuroprotectins, resolvins, maresins) and endocannabinoid-like metabolites [2, 9, 11-18].

Brain DHA levels rely on dietary content [19]. DHA is either synthesized from the essential PUFA alphalinolenic acid (ALA, 18:3 n-3) or consumed preformed from marine sources $[20,21]$. Despite the brain expressing the enzymes necessary to synthesize DHA from ALA, the synthesis rate is much lower than the rate of DHA uptake from the plasma, suggesting that the diet is a primary source of DHA to the brain [22-24]. Once ingested, DHA is rapidly redistributed within (1) plasma lipoproteins, mainly in triacylglycerols (TG) or phospholipids (PL) (which constitute the major destination for DHA) and (2) the albumin fraction as non-esterified DHA or lysophosphatidylcholine-esterified DHA (lyso PC-DHA) in the blood [25-27].

Several works report that the bioavailability of DHA to the brain is better when DHA is in its lysoPC form in the blood [28-31]. However, how DHA enters the brain is still a matter of debate as both unesterified and lysoPC-DHA forms are good source of brain DHA [26, 32]. Several reports are in favor of a preferential crossing of the bloodbrain barrier (BBB) when DHA is esterified at the sn-2 position of lysoPC-DHA [28, 31]. This is supported by the recent discovery of MFSD2A (major facilitating superfamily domain-containing protein $2 \mathrm{~A}$ ), an exclusive transporter of lysoPC-DHA expressed by endothelial cells of $\mathrm{BBB}$ [33]. Importantly, in regard to brain diseases, DHA in the form of lysophospholipid has a longer plasma half-life and, as a result, increases DHA brain exposure [26].

In the lysoPC form, DHA is initially esterified at the sn-2 position. However, it rapidly changes from the physiological sn-2 position to the more stable but nonphysiological sn-1 position. Then, to prevent such a migration, we acetylated the sn-1 position that results in a structured phospholipid, 1-acetyl,2-docosahexaenoylPC (AceDoPC) [34]. This structure mimics and behaves like 2-DHA-lysoPC in terms of DHA accumulation in the brain and has been shown to exert different biological properties such as the prevention of experimental stroke or the inhibition of the platelet-activating factorinduced aggregation in rats [34, 35].

Despite the possibility of a privileged entry of AceDoPC in the brain [36], its potential effect on neuroinflammatory pathways has not been explored. In this work, we investigated the effects of AceDoPC as compared to PC-DHA(1-palmitoyl,2-docosahexaenoyl-PC), previously shown to also increase delivery of DHA to brain when acutely administered [4]. We tested this in lipopolysaccharide (LPS)-induced neuroinflammation in both in vitro and in vivo models and probed the underlying signaling mechanisms. We found that a single in vivo administration of AceDoPC or PC-DHA specifically reduced LPS-induced interleukin-6 (IL-6), a proinflammatory cytokine, in the hippocampus but not in the hypothalamus. In vitro, AceDoPC significantly decreased microglia activation and IL-6-induced nuclear translocation of STAT3 in microglia cells through the downregulation of IL-6 receptor subunit gp130. AceDoPC effect on microglia and neuroinflammatory pathways suggests a potential therapeutic avenue for inflammationrelated brain diseases.

\section{Methods}

\section{Animals and treatments}

Animal husbandry and experimental procedures were in accordance with the EU Directive 2010/63/EU for animal experiments and approved by the national ethical committee for care and use of animals (approval ID A13169). C57BL6/J mice from Janvier (Le Genest St Isle, France) were received at 10 weeks of age, housed individually and maintained in a temperature $\left(22 \pm 1^{\circ} \mathrm{C}\right)$ and humidity controlled facility on a $12 \mathrm{~h}$ light-dark cycle with free access to food and water. They were fed a standard chow diet (A04, Safe, Augy, France). Experiments were performed at 12 weeks of age. The day before the experiment, plasma from $\mathrm{C} 57 \mathrm{BL} / 6 \mathrm{~J}(n=10)$ was isolated as previously described [35]. Briefly, mouse blood was collected in tubes containing heparin and centrifuged for $10 \mathrm{~min}$ at $2600 \mathrm{~g}$. Plasma was collected and incubated overnight at $4{ }^{\circ} \mathrm{C}$ with AceDoPC [34] or PC-DHA [34] or vehicle. Then, the mice were injected intravenously in the caudal vein at the following concentrations: $3.23 \mu \mathrm{g} / \mathrm{g}$ of mouse for AceDoPC and $4.33 \mu \mathrm{g} / \mathrm{g}$ of mouse for PC-DHA. Doses of AceDoPC and PC-DHA administrated are equivalent to $1.7 \mu \mathrm{g} /$ mouse or $\approx 66 \mu \mathrm{M} /$ mouse of DHA/mouse. Twentyfour hours after injection, mice were injected intraperitoneally with LPS (Escherichia coli 0127:B8, $500 \mu \mathrm{g} / \mathrm{kg})$ or $\mathrm{NaCl}(n=3-6$ per group) [20,37]. Mice were sacrificed $6 \mathrm{~h}$ later by decapitation after isoflurane anesthesia. Hippocampus and hypothalamus were quickly collected, frozen on dry ice and stored at $-80{ }^{\circ} \mathrm{C}$ until analysis. Blood samples were obtained 
by cardiac puncture and collected in tubes containing $10 \%$ EDTA. After $10 \mathrm{~min}$ centrifugation $\left(10,000 \mathrm{~g}, 4{ }^{\circ} \mathrm{C}\right)$, plasma was collected and kept at $-80{ }^{\circ} \mathrm{C}$.

\section{Cell culture and treatments}

BV-2 cells, an immortalized murine microglial cell line, were cultured as previously described [16] in RPMI medium (Invitrogen, Carlsbad, CA, USA) supplemented with $10 \%$ heat-inactivated fetal calf serum (Eurobio, Courtaboeuf, France), streptomycin sulfate $(50 \mu \mathrm{g} / \mathrm{mL})$, phenoxypenicillinic acid $(65 \mu \mathrm{g} / \mathrm{mL})$, and glutamine $(65 \mu \mathrm{g} / \mathrm{mL})$ in $5 \% \mathrm{CO}_{2}$ at $37{ }^{\circ} \mathrm{C}$. Cells were seeded at a density of 500,000 cells/well in 6-well culture plates. When cells reached $75 \%$ confluency, they were serumstarved for $24 \mathrm{~h}$ in RPMI. Then, they were treated for $24 \mathrm{~h}$ in serum-free medium containing $50 \mu \mathrm{mol} / \mathrm{L}$ fatty acid-free bovine serum albumin (BSA, Sigma Aldrich) added with PC-DHA $(30 \mu \mathrm{M})$ or AceDoPC $(30 \mu \mathrm{M})$ in $0.1 \%$ ethanol or $0.1 \%$ ethanol used as vehicle. These concentrations were chosen on the basis of optimal biological effects of DHA previously reported [2]. In addition, the solvent used $(0.1 \%$ ethanol) has no effect on cytokine production and cell viability $[2,16]$. Where specified, cells were further treated with $1 \mu \mathrm{g} / \mathrm{mL}$ LPS $(E$. coli, 0127:B8, Sigma Aldrich, Lyon, France) for 3 or $6 \mathrm{~h}$ or with $10 \mathrm{ng} / \mathrm{mL}$ interleukin-6 (IL-6, R\&D Systems, Lille, France) diluted in $\mathrm{NaCl}$ for 30,60 , or $90 \mathrm{~min}$. BV-2 cells treated with $\mathrm{NaCl}$ alone were used as control $[2,16]$.

\section{Plasma cytokine assay}

Cytokine assays were performed as previously described [8]. The limit of detection was $1.1 \mathrm{pg} / \mathrm{ml}$ for IL-6, $2.3 \mathrm{pg} / \mathrm{ml}$ for TNF $\alpha, 5.4 \mathrm{pg} / \mathrm{ml}$ for IL-1 $\beta, 1.1 \mathrm{pg} / \mathrm{mL}$ for IFN $\gamma$, and $2.0 \mathrm{pg} / \mathrm{mL}$ for IL-10. Briefly, samples diluted $1 / 2$ were added to a 96 -well microtiter plate $(25 \mu \mathrm{L} /$ well $)$ coated with beads (Millipore, France), covered with aluminum foil, and incubated overnight on a shaker at $4{ }^{\circ} \mathrm{C}$ in the dark. After removal of sample using a magnet, beads were incubated with detection antibodies for $1 \mathrm{~h}$ at room temperature while shaking, followed by streptavidin-PE for $30 \mathrm{~min}$. The beads were then resuspended in $150 \mu \mathrm{L}$ sheath fluid and analyzed using the BioPlex 200 system (Bio-Rad, France). The reader was set to read a minimum of 50 beads with an identical fluorescence expressed as the median fluorescence intensity. Median fluorescence intensity readings were converted to $\mathrm{pg} / \mathrm{mL}$ using calibration curves prepared with cytokine standards included in the kit.

\section{RT-PCR}

Total RNA were extracted from brain structures and BV-2 cells using Trizol (Invitrogen, Life Technologies). RNA purity and concentration were determined using a Nanodrop spectrophotometer (Nanodrop technologies,
Wilmington, DE). One microgram of RNA was reverse transcribed to synthesize cDNA using Superscript III and oligo random hexamers (Invitrogen, Life Technologies $^{\mathrm{Tm}}$, Saint-Aubin, France) [5]. Quantitative PCR was then performed using the Applied Biosystems Assay-onDemand Gene Expression Products protocol (Foster City, CA, USA), as previously described [6]. Briefly, target cDNAs and reference cDNAs ( $\beta 2$-microglobulin) were amplified by PCR using Taqman gene expression assays for sequence-specific primers purchased from Applied Biosystems (Foster city, CA, USA) [3, 5, 38]. We focused on the expression levels of IL-1 $\beta$, IL-6, and TNF $\alpha$ as pro-inflammatory markers. Reactions were performed in duplicate according to manufacturer's instructions as previously described [39]. PCR program consisted of 40 cycles of $95{ }^{\circ} \mathrm{C}$ for $15 \mathrm{~s}$ and $60{ }^{\circ} \mathrm{C}$ for 1 min. Fluorescence was measured using an AB 7500 Real-Time PCR system (Applied Biosystems, Foster city, $\mathrm{CA}$ ), and final quantification was carried out using the comparative threshold $(\mathrm{Ct})$ method as previously described [3, 6, 7, 40]. Results are expressed as relative fold change to control target mRNA expression.

\section{FACS analysis}

BV-2 cells preparation was incubated with anti-CD16/ CD32 antibody (rat, eBiosciences, Paris, France) to block Fc receptors for $5 \mathrm{~min}$ on ice. Cells were washed and then incubated for $1 \mathrm{~h}$ with anti-gp80-PE (rat, Biolegend, Ozyme, France) and anti-gp130-APC (rat, eBiosciences, Paris, France). After washing, cells were then suspended in PBS/BSA $0.1 \%$ for analysis. Non-specific binding was assessed by using non-specific, isotype-matched antibodies (PE-Rat IgG2b א Isotype; APC-Rat IgG2a K Isotype, Biolegend). Antigen expression was determined using a Becton-Dickinson LSR Fortessa ${ }^{\mathrm{TM}}$ multicolor cytometer (Franklin Lakes, NJ, USA). Ten thousand events were recorded for each sample and isotype matchedconjugate. Data were analyzed using FlowJo software and gating for each antibody was determined based on non-specific binding of appropriate negative isotype stained controls [6].

\section{Western blot analysis}

After treatments, cells were washed twice in ice-cold phosphate-buffered saline (PBS) $0.1 \%$, scraped off, and centrifuged at $1500 \mathrm{rpm}$ for $10 \mathrm{~min}$ at $4{ }^{\circ} \mathrm{C}$. For protein extraction, cell pellets were homogenized in $100 \mu \mathrm{L}$ of lysis buffer (1 M TrisHCl pH 7.4, 0.5 M EDTA, $1 \mathrm{M}$ $\mathrm{MgCl}_{2}, 1 \mathrm{M}$ dithiothreitol, $1 \mathrm{M} \mathrm{Na}$ orthovanadate, 100 $\mathrm{mMNaF}$, and protease cocktail inhibitor) on ice. After incubation on ice for $30 \mathrm{~min}$, samples were centrifugated for $6 \mathrm{~min}$ at $6000 \mathrm{rpm}$ at $4{ }^{\circ} \mathrm{C}$. Protein concentration was assessed by bicinchoninic acid assay (Interchim, Montluçon, France), according to the manufacturer's 
instructions. Equal amounts of protein $(50 \mu \mathrm{g})$ were loaded and separated on SDS-polyacrylamide gels (10\%) and transferred onto polyvinyl difluoride membranes (Merck Millipore, Molsheim, France). Membranes were saturated with a blocking solution containing $5 \%$ nonfat dried milk and $0.05 \%$ Tween-20. Membranes were incubated overnight at $4{ }^{\circ} \mathrm{C}$ in a solution containing $5 \%$ BSA with the following primary antibodies: anti-phosphoSTAT3 (rabbit, Cell Signaling, 1:500), anti-STAT3 (rabbit, Santa cruz, 1:1000), and anti-actin (rabbit, Biolegend, 1:2500). After washing, membranes were incubated for $1 \mathrm{~h}$ at room temperature with a rabbit peroxidaseconjugated secondary antibody (1:5000, Jackson Immuno Research Laboratories, Westgrove, PA, USA). The blots were developed using Western Lighting Chemiluminescence Reagent Plus (PerkinElmer Life Science, Waltham, MA, USA). Chemiluminescence was captured by a
Syngene detection system and quantified by Gene Tools software (Syngene, Cambridge, UK). Between each revelation, membranes were incubated for $15 \mathrm{~min}$ in Re-Blot Plus Strong Antibody Stripping Solution (Merck Millipore, Molsheim, France) according to manufacturer's instructions in order to remove the previous antibody.

\section{Lipid analyses}

Total lipids from brain structures and BV-2 cell preparations were extracted according to the method of Folch et al. [41] and fatty acids were transmethylated according to the method of Morrison and Smith [42]. Fatty acid methyl esters (FAMEs) were analyzed on a FOCUS GC gas chromatograph (Thermo Electron Corporation) equipped with a split injector and a flame ionization detector. Separation of FAMEs was performed with a

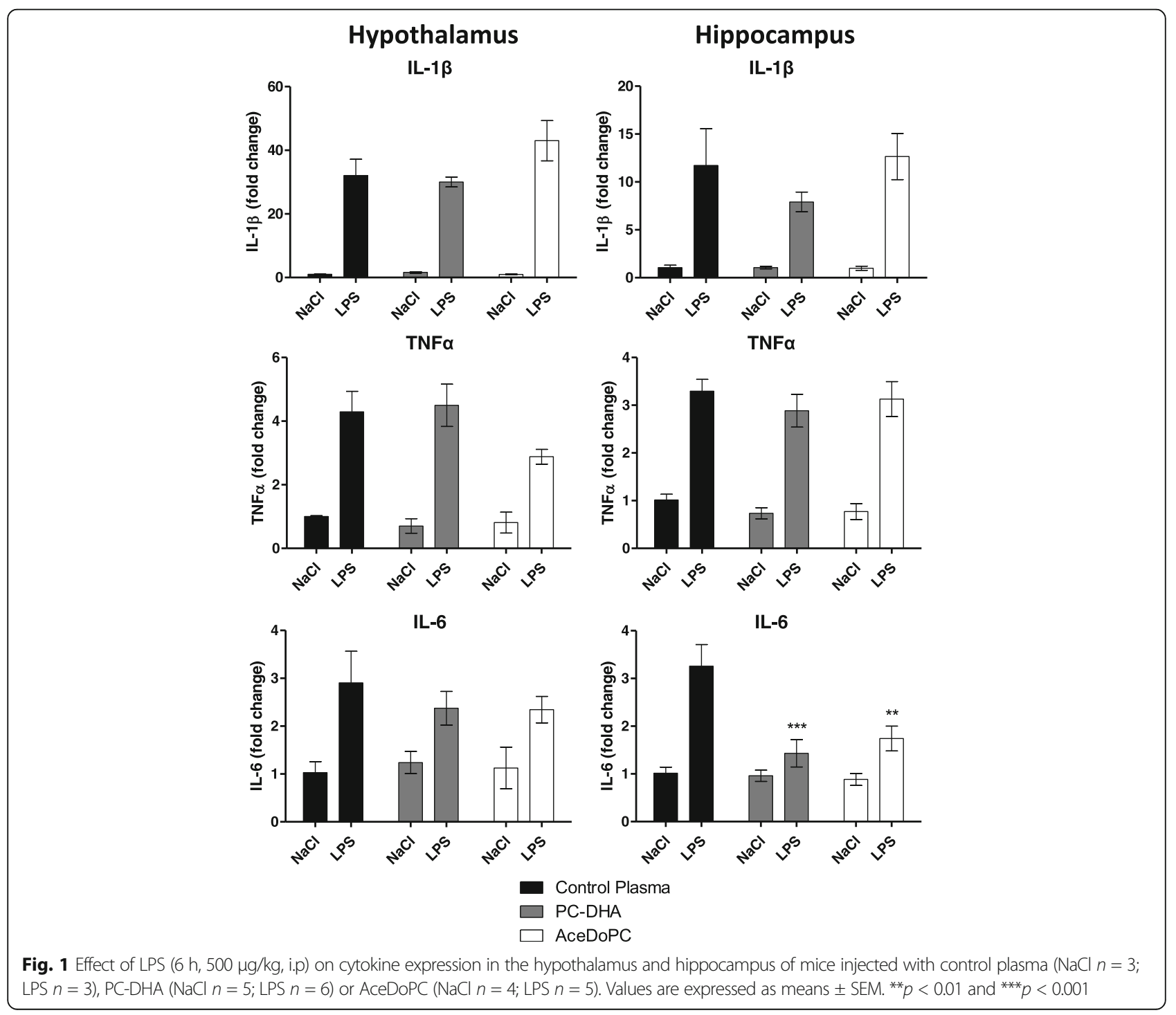


BPX70-fused silica capillary column $(60 \mathrm{~m}$ length $\times 0.22 \mathrm{~mm}$ internal diameter, $0.25 \mu \mathrm{m}$ film thickness; SGE, Courtaboeuf, France). The hydrogen inlet pressure was $100 \mathrm{kPa}$. The injector and detector temperatures were at 250 and $280{ }^{\circ} \mathrm{C}$, respectively. The oven was at $150{ }^{\circ} \mathrm{C}$, increased to $190{ }^{\circ} \mathrm{C}$ at a rate of $1.5^{\circ} \mathrm{C} \mathrm{min}-{ }^{1}$ with a 27 -min hold, and increased to $230{ }^{\circ} \mathrm{C}$ at a rate of $20{ }^{\circ} \mathrm{C} \mathrm{min}-{ }^{1}$ and then left at this temperature for $25 \mathrm{~min}$. FAMEs were identified by making a comparison with commercial standards. Fatty acid composition is expressed as the percentage of total fatty acids.

\section{Statistical analyses}

All data are expressed as means \pm standard error of the mean (SEM). Statistical significance between multiple groups was analyzed by two-way ANOVA (treatment $x$ LPS). When two-way ANOVA revealed a significant interaction, significant effects were analyzed by Fisher's LSD post hoc test. For all other measurements, experimental groups were compared using a one-way ANOVA analysis followed by Tukey's multiple comparison test. All statistical tests were performed using a critical probability of $p<0.05$.

\section{Results}

PC-DHA and AceDoPC attenuate LPS-induced IL-6 mRNA expression in the hippocampus

To investigate the potential anti-inflammatory effect of PC-DHA and AceDoPC, mice were injected i.v. with PCDHA or AceDoPC 24 h prior to i.p. LPS administration. LPS is known to induce pro-inflammatory cytokine expression in several brain structures, including the hippocampus and in the hypothalamus [43]. Pro-inflammatory cytokine mRNA expression was measured by RT-qPCR in these two brain structures $6 \mathrm{~h}$ after LPS injection (Fig. 1). LPS increased mRNA expression of IL-1 $1 \beta$, TNF $\alpha$, and IL-

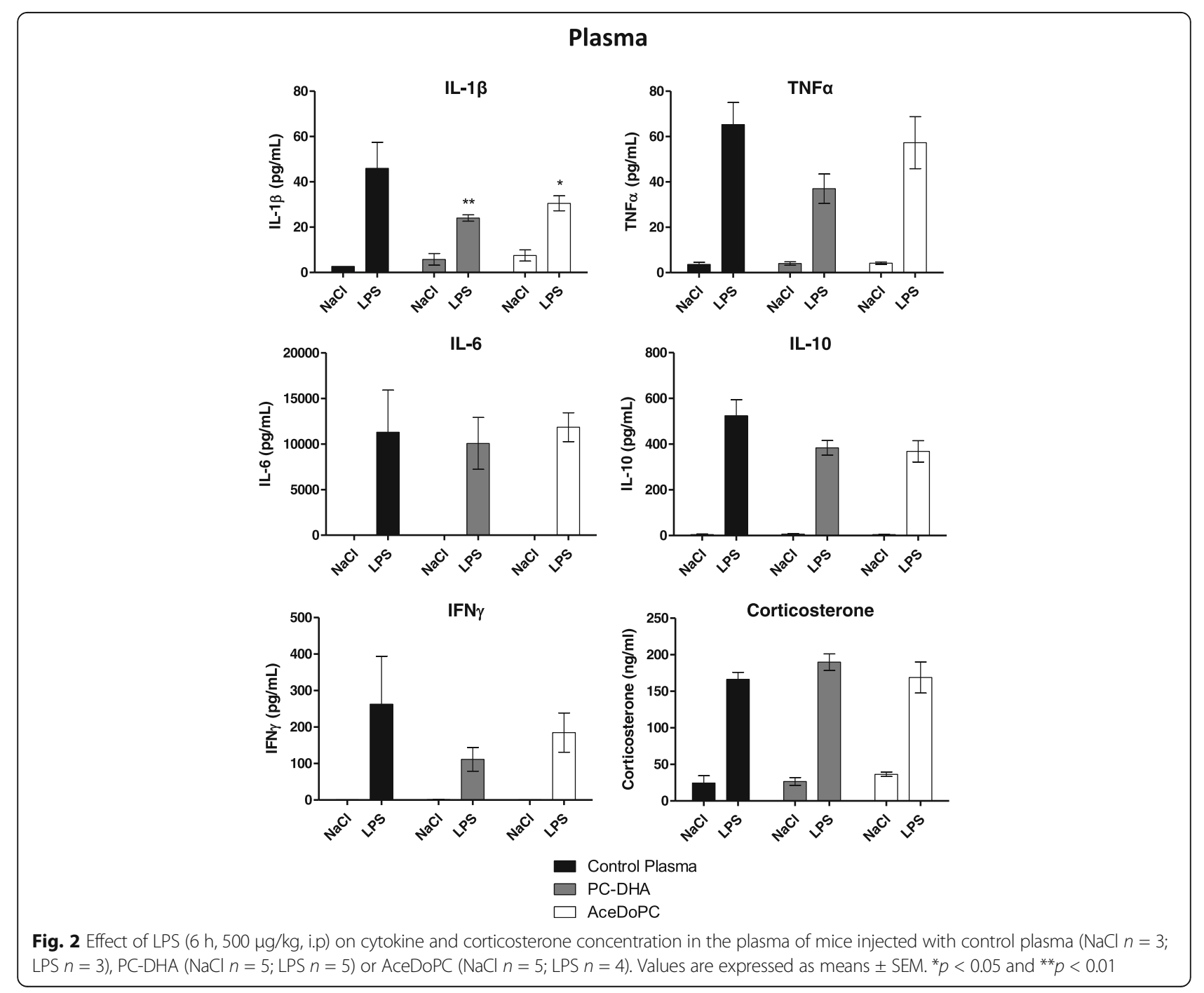


6 in both the hypothalamus and the hippocampus of the mice (hypothalamus: LPS effect IL-1 $\beta \mathrm{F}(1,18)=110.6$, $p<0.001$; TNF $\alpha \mathrm{F}(1,18)=47.30, p<0.001$; IL-6 F $(1$, $18)=18.57, p<0.001$; hippocampus: LPS effect IL-1 $\beta \mathrm{F}(1$, $22)=45.25, p<0.001$; TNF $\alpha \mathrm{F}(1,22)=81.99, p<0.001)$. The 2-way ANOVA analysis revealed a significant treatment $\times$ LPS interaction $(\mathrm{F}(2,22)=5405 p<0.05)$. Post-hoc analysis further revealed a significant effect of PC-DHA $(p<0.001)$ and of AcedoPC $(p<0.01)$ on LPSinduced IL-6 mRNA expression.

PC-DHA and AceDoPC effects on IL-6 mRNA expression in the hippocampus are not associated with changes in plasma IL-6 concentration

To evaluate if PC-DHA and AceDoPC have an effect on peripheral inflammatory response, we then measured the concentration of pro- and anti-inflammatory cytokines in the plasma of mice $6 \mathrm{~h}$ after LPS injection (Fig. 2). LPS induced a significant increase in pro-inflammatory and antiinflammatory cytokine concentration (LPS effect: TNF $\alpha$ $\mathrm{F}(1,20)=85.81, p<0.001$; IL-6 F $(1,18)=31.33, p<0.001$; IFN $\gamma \mathrm{F}(1,20)=24.68, p<0.001 ; \mathrm{IL}-10 \mathrm{~F}(1,19)=260.1$, $p<0.001)$ along with an increase in plasma corticosterone levels (LPS effect, $\mathrm{F}(1,19)=213.0, p<0.001$ ). No significant effect of PC-DHA and AceDoPC was observed for TNF $\alpha$, IL-6, IL-10, IFN $\gamma$, and corticosterone levels. Only LPSinduced IL-1 $\beta$ was significantly reduced in mice injected with PC-DHA or AceDoPC in comparison with vehicletreated mice (interaction treatment $\times \operatorname{LPS}, \mathrm{F}(2,19)=4.810$, $p<0.05)$. Hence, PC-DHA and AceDoPC effect on IL-6 mRNA levels in the hippocampus was not associated with an effect on IL-6 levels at the periphery.

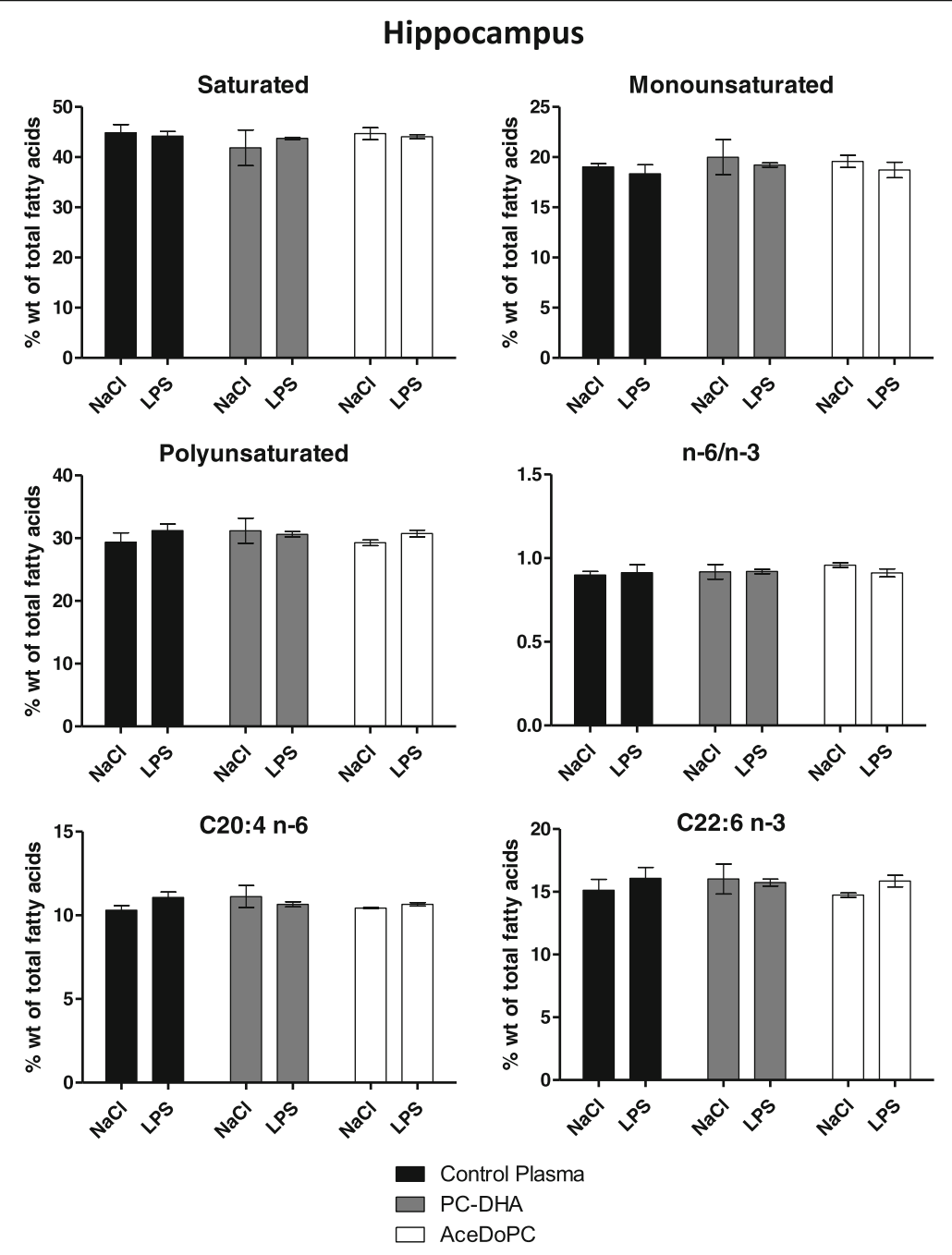

Fig. 3 Effect of LPS ( 6 h, $500 \mu \mathrm{g} / \mathrm{kg}$, i.p) treatment on fatty acid composition in the hippocampus of mice injected with control plasma (NaCl $n=3$; LPS $n=3)$, PC-DHA ( $\mathrm{NaCl} n=5$; LPS $n=6)$ or Acedo-PC ( $\mathrm{NaCl} n=5$; LPS $n=6)$. Values are expressed as means \pm SEM. C20:4 n-6: arachidonic acid; C22:6 n-3: docosahexaenoic acid 
PC-DHA and AceDoPC effects in the hippocampus are not associated to fatty acid composition changes

Fatty acids are known to modulate inflammatory response in the brain, especially in the hippocampus; therefore, we assessed the fatty acid content in this brain structure (Fig. 3). Both PC-DHA and AceDoPC treatments did not change the fatty acid composition in the hippocampus. Moreover, our data showed that $6 \mathrm{~h}$ LPS did not alter either the fatty acid composition of this brain structure. Hence, PC-DHA and AceDoPC effects on brain inflammatory response to LPS were not due to changes in hippocampus fatty acid composition.

Both PC-DHA and AceDoPC attenuate LPS-induced IL-6 mRNA expression in BV-2 cells

Because PC-DHA and AceDoPC effects in the hippocampus could be due to a direct effect on microglia, the immune cells of the brain, we then assessed their anti-inflammatory effect in vitro, in BV-2 cells. Cells were incubated for $24 \mathrm{~h}$ with PC-DHA, AceDoPC, or their control vehicle. LPS-stimulation (3 and $6 \mathrm{~h}$ ) induced an increase in IL-1 $\beta$, TNF $\alpha$, and IL- 6 mRNA expression in comparison to $\mathrm{NaCl}$ in vehicle-treated cells (Fig. 4). PC-DHA decreased LPS-induced IL-6 mRNA expression 3 and $6 \mathrm{~h}$ after stimulation (interaction treatment $\times$ LPS: $3 \mathrm{~h} \mathrm{~F}(2,12)=12.25, p<0.01 ; 6 \mathrm{~h} \mathrm{~F}(2$, $12)=36.88, p<0.001)$. Moreover, AceDoPC decreased IL-6 mRNA expression $6 \mathrm{~h}$ after LPS stimulation in comparison with vehicle group. These effects were specific to IL-6. Indeed, we did not observe any effect of treatments on LPS-induced TNF $\alpha$ mRNA expression and only an effect of PC-DHA on IL-1 $\beta$ mRNA expression 3 and $6 \mathrm{~h}$ after LPS stimulation (interaction treatment $\times$ LPS: 3 h F $(2,12)=10.70, p<0.01 ; 6$ h F $(2$, $12)=8.75, p<0.01)$.

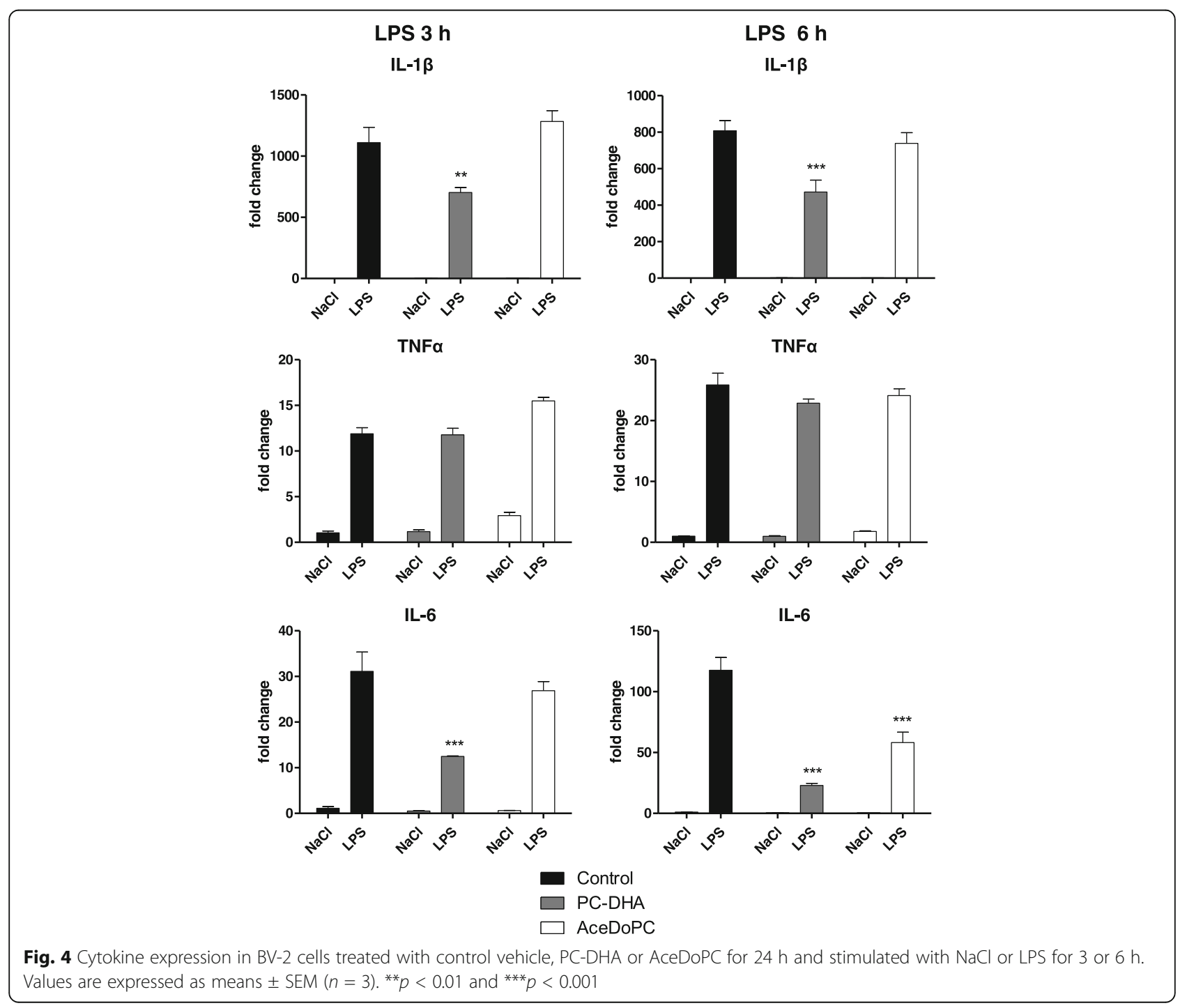




\section{AceDoPC decreases IL-6 receptor subunits surface expression in microglial cells}

We then investigated by flow cytometry analysis whether PC-DHA and AceDoPC exerted their effects on IL-6 expression in BV-2 cells via the IL-6 receptor. We evaluated the BV-2 cell surface expression of gp80 and gp130, two subunits of the IL-6 receptor, after $24 \mathrm{~h}$ lipid treatment and $0,30,60$, or 90 min stimulation with IL-6 (Fig. 5). Lipid treatment and IL-6 did not change the expression of gp80 subunit. However, gp130 expression decreased after AceDoPC treatment (treatment effect: $30 \min F=4.072, p<0.05 ; 60 \min F=5.369, p<0.05$; $90 \min F=17.46, p<0.001)$. PC-DHA decreased gp130 expression only $90 \mathrm{~min}$ after LPS treatment (treatment effect: $90 \min F=2.140, p<0.01)$.

\section{AceDoPC decreases IL-6-induced STAT3 activation}

Due to the effect of AceDoPC on IL-6 receptor subunit expression, we then assessed if the activation of the proinflammatory signaling pathway associated with the IL-6 receptor, the STAT3 pathway, was different under IL-6 stimulation (Fig. 6). When the cells were treated with AceDoPC, 30-min IL-6 treatment decreased STAT3 phosphorylation in comparison to vehicle- and PC-DHA-treated microglial cells (treatment effect: $F=3.850, p<0.05$ ). These results suggest that AceDoPC not only had an effect

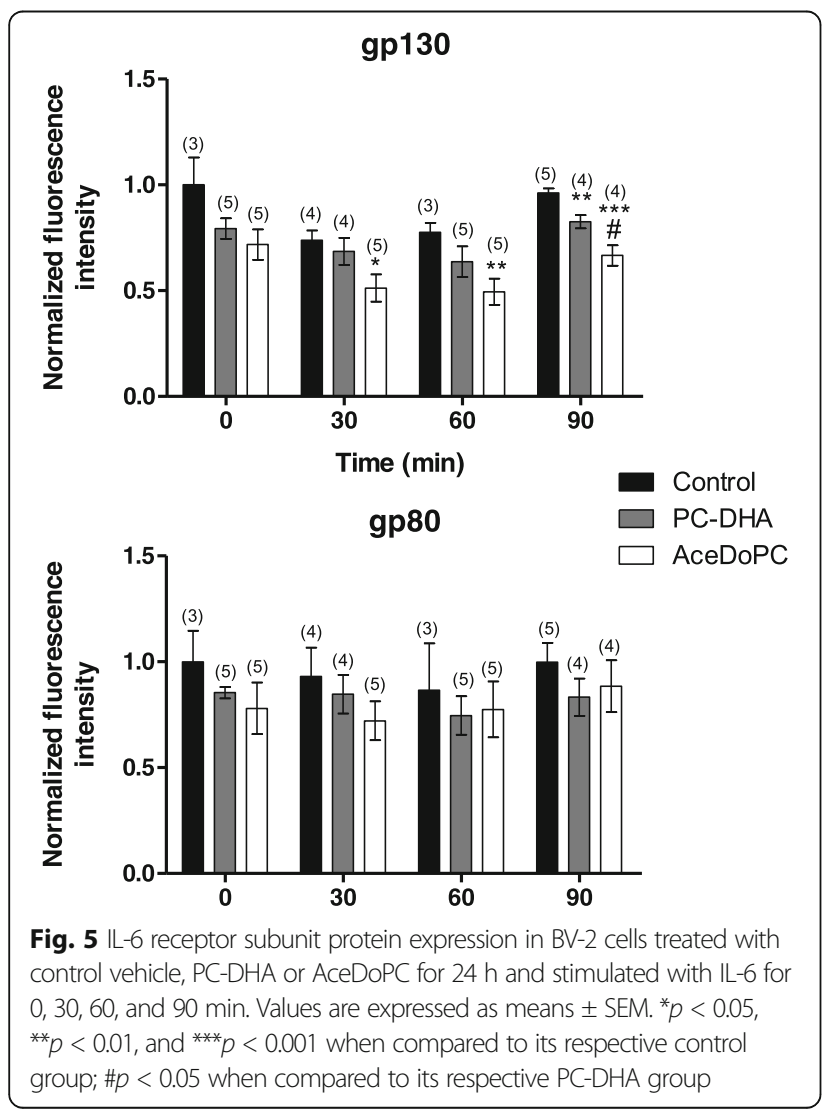

on IL-6 expression but also on its receptor and its associated signaling pathway.

\section{BV-2 fatty acid composition}

Finally, to test whether PC-DHA and AceDoPC affect the fatty acid composition of BV-2 cells, fatty acid contents were assessed by gas chromatography. Table 1 shows that both treatments induced a significant increase in n-3 PUFAs (treatment effect: $F=379.6$, $p<0.001)$, and specifically in DHA (22:6 n-3) (treatment effect: $F=542.8, p<0.001)$, inducing a decrease in $n-6 /$ n-3 ratio (treatment effect: $F=118.2, p<0.001$ ). Moreover, data showed that AceDoPC treatment significantly decreased the amount of saturated fatty acids in the membrane of BV-2 cells in comparison with vehicletreated cells (treatment effect: $F=5.218, p<0.05$ ).

\section{Discussion}

In this work, we found that in vivo, a single injection of AceDoPC or PC-DHA decreases LPS-induced IL-6 production in the hippocampus of mice. To further understand whether the effect of these molecules was due to their activity on microglia, we tested their activity in vitro. Our results revealed that both AceDoPC and PC-DHA were able to decrease LPS-induced IL-6 expression, while PC-DHA had also an effect on IL-1 $\beta$. In addition, these molecules reduced IL-6 receptor surface expression while only AceDoPC decreased IL-6-induced STAT3 phosphorylation. Altogether, these results highlight the potency of AceDoPC to regulate IL-6 production and signaling in microglia.

In the last decade, DHA has been recognized as a molecule with anti-inflammatory activity in the brain $[1,44]$. This activity is thought to be linked to its direct [14] or indirect [16] effect on microglia, thereby opening strategies for their use in several brain diseases with an inflammatory component [45]. In rodents, brain DHA increase through dietary, genetically or pharmacologically means protects from neuroinflammation linked to aging [5], pro-inflammatory treatment $[3,14,46]$, or acute injury [47-49]. Importantly, the acute increase of DHA in the hippocampus of mice is sufficient to attenuate neuroinflammatory processes triggered by the i.c.v. administration of LPS $[4,9]$. Conversely, rodent studies with n-3 PUFA dietary deficiencies leading to decreased DHA brain levels result in increased inflammatory cytokine expression, in particular IL-6 in the brain [7, 8, 50]. In humans, lower levels of blood DHA were associated to higher IL-6 levels and depression/anxiety scores after an interferon treatment or in healthy young adults [51-53]. Interestingly, EPA and DHA supplementation reduce inflammatory markers in depressed subjects [54]. However, whether a single, acute administration of DHA controls neuroinflammation has not been evaluated. Repeated intraperitoneal administration of DHA decreases neuroinflammatory 


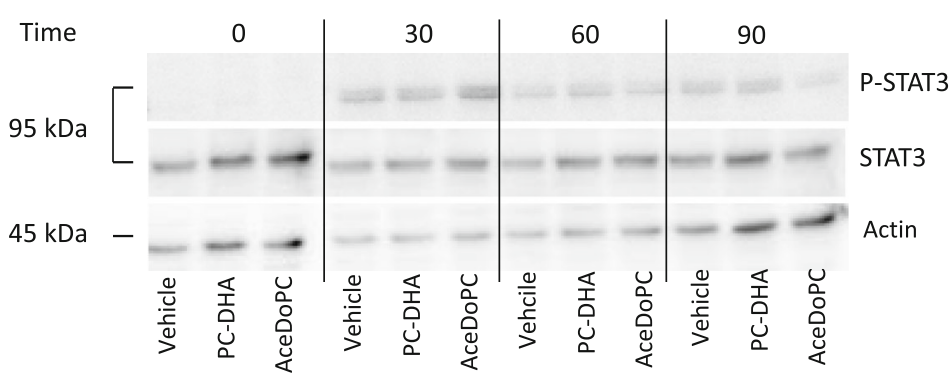

total STAT3

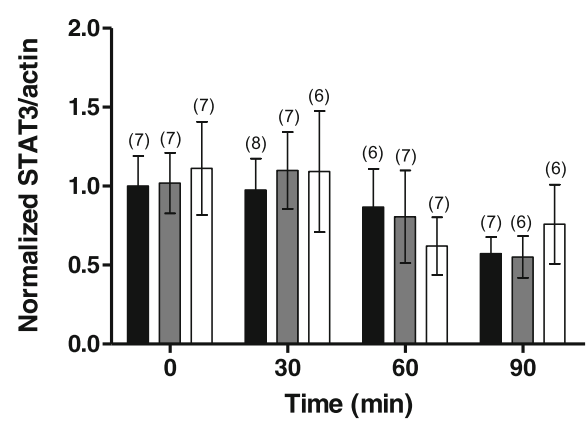

Phospho-STAT3/STAT3

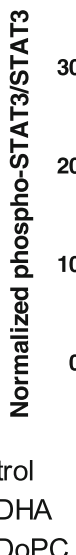

Fig. 6 STAT3 protein expression and activation in BV-2 cells treated with control vehicle, PC-DHA or AceDoPC for 24 h and stimulated with IL-6 for 0, 30, 60, and 90 min. Values are expressed as means \pm SEM. ${ }^{*} p<0.05$ when compared to its respective control group; \#p $<0.05$ when compared to its respective PC-DHA group

pathways activated by traumatic brain injury in rats [55]. Recent work reports that intravenous administration of unesterified DHA induces a transient increase in plasma DHA [56] with a rapid brain uptake [26]. Importantly, DHA, when consumed as phospholipid (PL) forms, enters the brain more effectively than as triglyceride forms $[4,57]$. In addition, if the plasma non-esterified DHA is sufficient to replace the brain DHA pool, the longer half-life of lysoPC-DHA allows for a longer brain exposure to DHA [26]. This is in line with the discovery of the presence of MFSD2A at the $\mathrm{BBB}$, a specific transporter of DHA in the lysoPC form [33]. We tested the effect of AceDoPC that mimics lysoPC [34] on LPS brain inflammatory response and compared it to PC-DHA. In vivo, both forms decreased LPS-induced IL-6 production in the hippocampus, but not in the hypothalamus. This suggests that these molecules equally targeted the hippocampus. However, this could be independent of their brain accumulation, as we could not detect any increase of DHA in the hippocampus (Fig. 3). This is in line with the work of Bazinet's group, who elegantly demonstrated that the unesterified DHA pool, but not the total phospholipid DHA, is critical to regulate i.c.v. LPS-induced cytokine production in the hippocampus $[4,9]$. However, as DHA was only measured in the whole hippocampus, we cannot rule out that DHA accumulates in specific substructures such as the BBB or a specific cell type, such as microglia. Further studies are warranted to elucidate this point. The long lasting effect of AceDoPC and PC-DHA $6 \mathrm{~h}$ after LPS administration could be linked to their longer half-life in the plasma and in the brain [26].

We cannot exclude that the anti-inflammatory effect of administered forms of DHA on hippocampal IL-6 is due to their peripheral effect. Indeed, both molecules decreased IL- $1 \beta$ in the plasma of LPS-treated mice, which could influence IL- 6 brain level as IL- $1 \beta$ has been shown to be the main cytokine activating IL- 6 production in the brain [58]. Of note, crawling monocytes are detected in cerebral vasculature of LPS-treated mice [37] and could be directly targeted by AceDoPC and PC-DHA before entering the brain, therefore producing less cytokine. However, monocyte entry is dependent on TNF $\alpha$ $[20,37]$ that is not downregulated by AceDoPC or PCDHA. As only hippocampal, and not hypothalamic IL-6 expression is affected by DHA, together with the fact that the hippocampus is more sensitive to DHA variation [19], we speculate that DHA targets this structure. This direct effect of esterified form of DHA is consistent with previous studies showing that a single injection of DHA reduces microglia activation after spinal cord 
Table 1 Fatty acid composition of BV-2 cells treated with control vehicle, PC-DHA, or AceDoPC for 24 h. Values are expressed as means $\pm \operatorname{SEM}(n=4)$

\begin{tabular}{|c|c|c|c|c|}
\hline & Control $n=4$ & PC-DHA $n=4$ & Acedo-PC $n=4$ & $p$ value \\
\hline & \multicolumn{4}{|c|}{ mg/100 mg fatty acids } \\
\hline $\mathrm{c} 12: 0$ & $3.1 \pm 0.30$ & $1.6 \pm 0.79^{*}$ & $1.3 \pm 0.54^{*}$ & 0.01 \\
\hline c14:0 & $7.1 \pm 0.23$ & $5.4 \pm 1.48$ & $4.4 \pm 1.27^{*}$ & 0.05 \\
\hline c15:0 & $0.4 \pm 0.03$ & $0.4 \pm 0.01$ & $0.4 \pm 0.02$ & 0.46 \\
\hline $\mathrm{c} 16: 0$ & $23.9 \pm 0.82$ & $21.1 \pm 1.83$ & $21.5 \pm 1.17$ & 0.07 \\
\hline $\mathrm{c} 17: 0$ & $0.3 \pm 0.01$ & $0.3 \pm 0.01$ & $0.2 \pm 0.01$ & 0.54 \\
\hline c18:0 & $9.3 \pm 0.20$ & $9.8 \pm 0.43$ & $10.5 \pm 0.82$ & 0.07 \\
\hline $\mathrm{c} 20: 0$ & $0.5 \pm 0.30$ & $0.2 \pm 0.01$ & $0.2 \pm 0.02^{*}$ & 0.04 \\
\hline $\mathrm{c} 22: 0$ & $0.3 \pm 0.04$ & $0.3 \pm 0.06$ & $0.3 \pm 0.02$ & 0.13 \\
\hline c24:0 & $0.9 \pm 0.04$ & $1.0 \pm 0.09$ & $0.9 \pm 0.04$ & 0.25 \\
\hline Saturated & $45.6 \pm 0.74$ & $40.0 \pm 3.56$ & $39.7 \pm 2.36^{*}$ & 0.04 \\
\hline c16:1n-9 & $3.0 \pm 0.07$ & $3.4 \pm 0.22^{*}$ & $3.2 \pm 0.15$ & 0.04 \\
\hline$c 16: 1 n-7$ & $2.5 \pm 0.07$ & $2.6 \pm 0.12$ & $2.7 \pm 0.10$ & 0.08 \\
\hline $\mathrm{c} 18: 1 \mathrm{t}$ & $2.1 \pm 0.36$ & $0.8 \pm 0.24^{* * *}$ & $0.6 \pm 0.04^{* * *}$ & $<0.0001$ \\
\hline c18:1 n-9 & $22.3 \pm 0.56$ & $23.0 \pm 1.40$ & $23.5 \pm 0.84$ & 0.40 \\
\hline c18:1 n-7 & $8.2 \pm 0.14$ & $9.1 \pm 0.44^{*}$ & $9.4 \pm 0.44^{* *}$ & 0.01 \\
\hline c20:1 n-9 & $0.6 \pm 0.01$ & $0.6 \pm 0.07$ & $0.6 \pm 0.05$ & 0.71 \\
\hline$c 24: 1$ n-9 & $1.3 \pm 0.03$ & $1.5 \pm 0.11 a^{*}$ & $1.6 \pm 0.10^{*}$ & 0.01 \\
\hline Monounsaturated & $40.0 \pm 0.80$ & $41.0 \pm 2.16$ & $41.5 \pm 1.53$ & 0.52 \\
\hline c18:2 n-6 & $0.3 \pm 0.02$ & $0.3 \pm 0.03$ & $0.3 \pm 0.04$ & 0.92 \\
\hline$c 20: 4 n-6$ & $1.4 \pm 0.08$ & $1.4 \pm 0.10$ & $1.4 \pm 0.09$ & 0.86 \\
\hline$c 22: 4 n-6$ & $0.2 \pm 0.03$ & $0.1 \pm 0.02$ & $0.1 \pm 0.01$ & 0.08 \\
\hline$c 22: 5 n-6$ & $0.1 \pm 0.02$ & $0.1 \pm 0.01$ & $0.1 \pm 0.01$ & 0.07 \\
\hline$n-6$ & $2.0 \pm 0.10$ & $1.9 \pm 0.10$ & $1.9 \pm 0.11$ & 0.64 \\
\hline$c 18: 3 n-3$ & $0.2 \pm 0.01$ & $0.2 \pm 0.01$ & $0.2 \pm 0.02$ & 0.26 \\
\hline$c 22: 5 n-3$ & $0.3 \pm 0.12$ & $0.4 \pm 0.22$ & $0.4 \pm 0.02$ & 0.43 \\
\hline$c 22: 6 n-3$ & $0.6 \pm 0.08$ & $3.7 \pm 0.19^{* * *}$ & $3.9 \pm 0.11^{* * *}$ & $<0.0001$ \\
\hline$n-3$ & $1.1 \pm 0.19$ & $4.3 \pm 0.21^{* * *}$ & $4.6 \pm 0.13^{* * *}$ & $<0.0001$ \\
\hline$c 20: 3 n-9$ & $5.9 \pm 0.07$ & $6.3 \pm 0.68$ & $5.8 \pm 0.44$ & 0.34 \\
\hline Polyunsaturated & $9.0 \pm 0.32$ & $12.5 \pm 0.95^{* * *}$ & $12.3 \pm 0.61^{* * *}$ & $<0.0001$ \\
\hline dma16:0 & $1.9 \pm 0.03$ & $2.5 \pm 0.15^{* *}$ & $2.5 \pm 0.13^{* * *}$ & $<0.0001$ \\
\hline dma18:0 & $0.9 \pm 0.03$ & $1.0 \pm 0.12$ & $1.1 \pm 0.10$ & 0.13 \\
\hline dma18:1 n-9 & $1.4 \pm 0.03$ & $1.6 \pm 0.13$ & $1.5 \pm 0.06$ & 0.07 \\
\hline dma18:1 n-7 & $1.2 \pm 0.02$ & $1.4 \pm 0.08^{*}$ & $1.4 \pm 0.08$ & 0.02 \\
\hline DMA & $5.4 \pm 0.10$ & $6.5 \pm 0.48^{*}$ & $6.5 \pm 0.35^{*}$ & 0.01 \\
\hline$n-6 / n-3$ & $1.8 \pm 0.26$ & $0.4 \pm 0.01^{* * *}$ & $0.4 \pm 0.01^{* * *}$ & $<0.0001$ \\
\hline
\end{tabular}

${ }^{*} p<0.05,{ }^{* *} p<0.01$, and ${ }^{* * *} p<0.001$ for comparison with control $D M A$ dimethylacetals, $P C$ phosphatidylcholine

injury $[59,60]$ or stroke $[13,61]$. However, additional in vivo experiments are warranted to determine whether AceDoPC and PC-DHA enter the hippocampus and target microglia to reduce IL-6 production in the context of LPS administration. In addition, according to our in vitro data showing that both IL-6 production and IL-6 signaling are downregulated by AceDoPC and PC-DHA, the analysis of their effect on IL-6 signaling in the hippocampus is of interest for future studies.

To assess whether AceDoPC and PC-DHA target microglia, which are the main cells producing proinflammatory cytokines in the brain in response to 
inflammatory stimuli, we assessed these cells in in vitro studies. Both molecules reduced LPS-induced IL-6 expression in microglia, with PC-DHA also reducing IL$1 \beta$. Of note, while DHA downregulated LPS-induced IL$1 \beta$ mRNA expression in vitro, it was not the case in vivo. Our previous work showed that DHA downregulated LPS-induced IL-1 $\beta$ release at high $(30 \mu \mathrm{M})$ but not low concentration $(0.3$ and $3 \mu \mathrm{M})$ [2], suggesting that a certain amount of DHA is required to regulate LPSinduced IL-1 $\beta$ synthesis and release in microglia. Here, we used $\approx 60 \mu \mathrm{M}$ of DHA in vivo and $30 \mu \mathrm{M}$ of DHA in vitro. In vitro, such dose is sufficient to increase DHA levels in microglia (Table 1). Whether the $60 \mu \mathrm{M}$ of DHA is sufficient to target microglia and IL- $1 \beta$ production in vivo remains to be demonstrated.

To our knowledge, this is the first study to test the anti-inflammatory activity of DHA esterified on phospholipids in microglia. Free DHA has been previously reported to reduce LPS-induced IL-1 $\beta$, IL-6, and TNF $\alpha$ through its effect on LPS receptors and signaling pathway [2]. Other mechanisms such as antioxidant activity [62] or lipid bodies and organelle reorganization [63, 64] have been demonstrated to mediate the anti-inflammatory activity of unesterified DHA. In this study, we identify an additional effect of AceDoPC on IL-6 receptors and STAT3 phosphorylation, which is a hallmark of IL-6 signaling pathway activation. IL-6-induced-STAT3 in the brain has been reported to be important in mediating the behavioral effect of LPS [7]. In addition, this pathway is regulated in vivo by DHA content in the brain [7]. DHA inhibitory effect on IL-6 activity has been previously reported in hepatocytes and osteoblasts, with a very specific effect $[65,66]$. Of note, DHA inhibitory effect on STAT3 phosphorylation has been previously reported to involve PPAR $\gamma[65,67]$. In human gastric epithelial cells, DHA increased the mRNA level of SOCS3, a negative regulator of STAT3 signaling [25, 67]. Interestingly, bacteria-induced STAT3 activation is reduced by DHA through a specific PPARY-SOCS3 (a negative regulator of STAT3 signaling) $[25,67]$. Whether this is the case in microglia in vitro and in vivo remains to be evaluated.

Previous work suggests that COX-2 upregulates IL-6 associated STAT3 signaling [68]. In an in vitro assay, AceDoPC reduces COX-2 activity (data not shown). In line with this, previous work conducted in macrophages revealed that DHEA, a DHA-derivative ethanolamide, downregulates COX-2 expression [26, 69]. However, whether AceDoPC's specific effect (direct or through derivatives) on the IL-6 signaling pathway involves COX-2 remains to be tested. An additional mechanism underlying AceDoPC's effects on IL-6 induced-STAT3 phosphorylation could be linked to the decreased expression of gp130, the co-receptor of IL-6. Recent studies highlight that gp130/STAT3 phosphorylation is involved in the pro- inflammatory activity of IL-6, while gp130 mediates IL-6 effect on tissue repair and recovery after infection [70]. Further studies are warranted to determine whether AceDoPC decreases brain IL-6 activity through its effect on gp130 in vivo.

\section{Conclusions}

These results show that AcedoPC modulates LPS-induced neuroinflammation and IL-6 signaling in microglia. As AcedoPC is a specific carrier of DHA and may increase its brain penetration, it represents a therapeutic application for treating neuroinflammation.

\section{Acknowledgements}

We thank Mathieu Cadet, Philippe Birac, and Claudine Tridon for their help in animal care. We also thank Madeleine Pick for the preparation of AceDoPC.

\section{Funding}

This work was supported by INRA (SL, CJ) and the ANR Neuroprotect (ANR07-PNRA-022, SL, ML). CF is the recipient of a doctoral support by Région Aquitaine and INRA (2013 13 03001). JRB is the recipient of a post-doc support by FRM (grant number DRM20101220441). AG is the recipient of an Agreenskill (INRA) grant.

Availability of data and materials

The data used in this article are available upon request.

Authors' contributions

SL, CJ, and ML designed the studies. CF, CJ, and JRB performed experiments. All authors analyzed and interpreted the results. SL, CJ, and CL were the major contributors in writing the manuscript. AG revised the manuscript and corrected it for the English grammar. All authors read and approved the final manuscript.

Ethics approval and consent to participate

Not applicable

Consent for publication

Not applicable

Competing interests

The authors declare that they have no competing interests.

\section{Publisher's Note}

Springer Nature remains neutral with regard to jurisdictional claims in published maps and institutional affiliations.

\section{Author details}

${ }^{1}$ INRA, Nutrition et Neurobiologie Intégrée, UMR 1286, 33076 Bordeaux, France. ${ }^{2}$ Bordeaux University, Nutrition et Neurobiologie Intégrée, UMR 1286, 33076 Bordeaux, France. ${ }^{3}$ CarMeN laboratory, INSERM UMR 1060, INRA UMR 1397, IMBL, INSA-Lyon, University of Lyon, Lyon, France.

Received: 7 June 2017 Accepted: 9 August 2017

Published online: 24 August 2017

References

1. Bazinet RP, Laye S. Polyunsaturated fatty acids and their metabolites in brain function and disease. Nat Rev Neurosci. 2014;15:771-85.

2. De Smedt-Peyrusse V, Sargueil F, Moranis A, Harizi H, Mongrand S, Laye S. Docosahexaenoic acid prevents lipopolysaccharide-induced cytokine production in microglial cells by inhibiting lipopolysaccharide receptor presentation but not its membrane subdomain localization. J Neurochem. 2008;105:296-307.

3. Delpech JC, Thomazeau A, Madore C, Bosch-Bouju C, Larrieu T, Lacabanne C, Remus-Borel J, Aubert A, Joffre C, Nadjar A, Laye S. Dietary n-3 PUFAs 
deficiency increases vulnerability to inflammation-induced spatial memory impairment. Neuropsychopharmacology. 2015;40:2774-87.

4. Kitson AP, Metherel AH, Chen CT, Domenichiello AF, Trepanier MO, Berger A, Bazinet RP. Effect of dietary docosahexaenoic acid (DHA) in phospholipids or triglycerides on brain DHA uptake and accretion. J Nutr Biochem. 2016;33:91-102.

5. Labrousse VF, Nadjar A, Joffre C, Costes L, Aubert A, Gregoire S, Bretillon L, Laye $S$. Short-term long chain omega 3 diet protects from neuroinflammatory processes and memory impairment in aged mice. PLoS One. 2012;7:e36861.

6. Madore C, Nadjar A, Delpech JC, Sere A, Aubert A, Portal C, Joffre C, Laye S. Nutritional n-3 PUFAs deficiency during perinatal periods alters brain innate immune system and neuronal plasticity-associated genes. Brain Behav Immun. 2014;41:22-31.

7. Mingam R, Moranis A, Bluthe RM, De Smedt-Peyrusse V, Kelley KW, Guesnet $P$, Lavialle M, Dantzer R, Laye S. Uncoupling of interleukin-6 from its signalling pathway by dietary $n$-3-polyunsaturated fatty acid deprivation alters sickness behaviour in mice. Eur J Neurosci. 2008;28:1877-86.

8. Moranis A, Delpech JC, De Smedt-Peyrusse V, Aubert A, Guesnet P, Lavialle M, Joffre C, Laye S. Long term adequate n-3 polyunsaturated fatty acid diet protects from depressive-like behavior but not from working memory disruption and brain cytokine expression in aged mice. Brain Behav Immun. 2012;26:721-31.

9. Orr SK, Palumbo S, Bosetti F, Mount HT, Kang JX, Greenwood CE, Ma DW, Serhan CN, Bazinet RP. Unesterified docosahexaenoic acid is protective in neuroinflammation. J Neurochem. 2013;127:378-93.

10. Orr SK, Trepanier MO, Bazinet RP. n-3 Polyunsaturated fatty acids in animal models with neuroinflammation. Prostaglandins Leukot Essent Fatty Acids. 2013;88:97-103.

11. Bazan NG, Marcheselli VL, Cole-Edwards K. Brain response to injury and neurodegeneration: endogenous neuroprotective signaling. Ann N Y Acad Sci. 2005;1053:137-47.

12. Calder PC. Marine omega-3 fatty acids and inflammatory processes: effects, mechanisms and clinical relevance. Biochim Biophys Acta. 2015;1851:469-84.

13. Eady TN, Khoutorova L, Atkins KD, Bazan NG, Belayev L. Docosahexaenoic acid complexed to human albumin in experimental stroke: neuroprotective efficacy with a wide therapeutic window. Exp Transl Stroke Med. 2012;4:19.

14. Hopperton KE, Trepanier MO, Giuliano V, Bazinet RP. Brain omega-3 polyunsaturated fatty acids modulate microglia cell number and morphology in response to intracerebroventricular amyloid-beta 1-40 in mice. J Neuroinflammation. 2016;13:257.

15. Meijerink J, Poland M, Balvers MG, Plastina P, Lute C, Dwarkasing J, van Norren K, Witkamp RF. Inhibition of COX-2-mediated eicosanoid production plays a major role in the anti-inflammatory effects of the endocannabinoid $\mathrm{N}$-docosahexaenoylethanolamine (DHEA) in macrophages. Br J Pharmacol. 2015;172:24-37.

16. Rey C, Nadjar A, Buaud B, Vaysse C, Aubert A, Pallet V, Laye S, Joffre C. Resolvin D1 and E1 promote resolution of inflammation in microglial cells in vitro. Brain Behav Immun. 2016;55:249-59.

17. Sheets KG, Jun B, Zhou Y, Zhu M, Petasis NA, Gordon WC, Bazan NG. Microglial ramification and redistribution concomitant with the attenuation of choroidal neovascularization by neuroprotectin D1. Mol Vis. 2013;19:1747-59.

18. Wang Y, Plastina P, Vincken JP, Jansen R, Balvers M, Ten Klooster JP, Gruppen H, Witkamp R, Meijerink J. N-docosahexaenoyl dopamine, an endocannabinoid-like conjugate of dopamine and the n-3 fatty acid docosahexaenoic acid, attenuates lipopolysaccharide-induced activation of microglia and macrophages via COX-2. ACS Chem Neurosci. 2017;8:548-57.

19. Joffre C, Gregoire S, De Smedt V, Acar N, Bretillon L, Nadjar A, Laye S. Modulation of brain PUFA content in different experimental models of mice. Prostaglandins Leukot Essent Fatty Acids. 2016;114:1-10.

20. Brenna JT, Diau GY. The influence of dietary docosahexaenoic acid and arachidonic acid on central nervous system polyunsaturated fatty acid composition. Prostaglandins Leukot Essent Fatty Acids. 2007;77:247-50.

21. Simopoulos AP. Evolutionary aspects of diet: the omega-6/omega-3 ratio and the brain. Mol Neurobiol. 2011;44:203-15.

22. Burdge G. Alpha-linolenic acid metabolism in men and women: nutritional and biological implications. Curr Opin Clin Nutr Metab Care. 2004;7:137-44.

23. Metherel AH, Domenichiello AF, Kitson AP, Hopperton KE, Bazinet RP. Whole-body DHA synthesis-secretion kinetics from plasma eicosapentaenoic acid and alpha-linolenic acid in the free-living rat. Biochim Biophys Acta. 1861;2016:997-1004
24. Plourde M, Cunnane SC. Extremely limited synthesis of long chain polyunsaturates in adults: implications for their dietary essentiality and use as supplements. Appl Physiol Nutr Metab. 2007;32:619-34.

25. Brossard N, Croset M, Lecerf J, Pachiaudi C, Normand S, Chirouze V, Macovschi O, Riou JP, Tayot JL, Lagarde M. Metabolic fate of an oral tracer dose of [13C]docosahexaenoic acid triglycerides in the rat. Am J Phys. 1996; 270:R846-54

26. Chen $C T$, Kitson $A P$, Hopperton $K E$, Domenichiello AF, Trepanier $M O$, Lin $L E$, Ermini L, Post M, Thies F, Bazinet RP. Plasma non-esterified docosahexaenoic acid is the major pool supplying the brain. Sci Rep. 2015;5:15791.

27. Lemaitre-Delaunay D, Pachiaudi C, Laville M, Pousin J, Armstrong M, Lagarde M. Blood compartmental metabolism of docosahexaenoic acid $(\mathrm{DHA})$ in humans after ingestion of a single dose of [(13)C]DHA in phosphatidylcholine. J Lipid Res. 1999;40:1867-74.

28. Bernoud N, Fenart L, Moliere P, Dehouck MP, Lagarde M, Cecchelli R, Lecerf J. Preferential transfer of 2-docosahexaenoyl-1-lysophosphatidylcholine through an in vitro blood-brain barrier over unesterified docosahexaenoic acid. J Neurochem. 1999;72:338-45.

29. Lagarde M, Bernoud N, Brossard N, Lemaitre-Delaunay D, Thies F, Croset M, Lecerf J. Lysophosphatidylcholine as a preferred carrier form of docosahexaenoic acid to the brain. J Mol Neurosci. 2001;16:201-4 discussion 215-21

30. Picq M, Chen P, Perez M, Michaud M, Vericel E, Guichardant M, Lagarde M. DHA metabolism: targeting the brain and lipoxygenation. Mol Neurobiol. 2010;42:48-51.

31. Thies F, Pillon C, Moliere P, Lagarde M, Lecerf J. Preferential incorporation of sn-2 lysoPC DHA over unesterified DHA in the young rat brain. Am J Phys. 1994;267:R1273-9.

32. Mitchell RW, Hatch GM. Fatty acid transport into the brain: of fatty acid fables and lipid tails. Prostaglandins Leukot Essent Fatty Acids. 2011;85:293-302.

33. Nguyen LN, Ma D, Shui G, Wong P, Cazenave-Gassiot A, Zhang X, Wenk MR, Goh EL, Silver DL. Mfsd2a is a transporter for the essential omega-3 fatty acid docosahexaenoic acid. Nature. 2014;509:503-6.

34. Lagarde M, Hachem M, Bernoud-Hubac N, Picq M, Vericel E, Guichardant M. Biological properties of a DHA-containing structured phospholipid (AceDoPC) to target the brain. Prostaglandins Leukot Essent Fatty Acids. 2015;92:63-5.

35. Hachem M, Geloen A, Van AL, Foumaux B, Fenart L, Gosselet F, Da Silva P, Breton G, Lagarde M, Picq M, Bernoud-Hubac N. Efficient docosahexaenoic acid uptake by the brain from a structured phospholipid. Mol Neurobiol. 2016;53:3205-15.

36. Lo Van A, Sakayori N, Hachem M, Belkouch M, Picq M, Lagarde M, Osumi N, Bernoud-Hubac N. Mechanisms of DHA transport to the brain and potential therapy to neurodegenerative diseases. Biochimie. 2016;130:163-7.

37. Audoy-Remus J, Richard JF, Soulet D, Zhou H, Kubes P, Vallieres L. Rodshaped monocytes patrol the brain vasculature and give rise to perivascular macrophages under the influence of proinflammatory cytokines and angiopoietin-2. J Neurosci. 2008;28:10187-99.

38. Labrousse VF, Costes L, Aubert A, Darnaudery M, Ferreira G, Amedee T, Laye S. Impaired interleukin-1 beta and c-Fos expression in the hippocampus is associated with a spatial memory deficit in P2X(7) receptor-deficient mice. PLoS One. 2009;4:e6006.

39. Dinel AL, Andre C, Aubert A, Ferreira G, Laye S, Castanon N. Cognitive and emotional alterations are related to hippocampal inflammation in a mouse model of metabolic syndrome. PLoS One. 2011;6:e24325.

40. Madore C, Joffre C, Delpech JC, De Smedt-Peyrusse V, Aubert A, Coste L, Laye S, Nadjar A. Early morphofunctional plasticity of microglia in response to acute lipopolysaccharide. Brain Behav Immun. 2013;34:151-8.

41. Folch J, Lees M, Sloane Stanley GH. A simple method for the isolation and purification of total lipides from animal tissues. J Biol Chem. 1957;226:497-509.

42. Morrison WR, Smith $L M$. Preparation of fatty acid methyl esters and dimethylacetals from lipids with boron fluoride-methanol. J Lipid Res. 1964;5:600-8.

43. Laye $S$, Parnet P, Goujon E, Dantzer R. Peripheral administration of lipopolysaccharide induces the expression of cytokine transcripts in the brain and pituitary of mice. Brain Res Mol Brain Res. 1994;27:157-62.

44. Lalancette-Hebert M, Julien C, Cordeau P, Bohacek I, Weng YC, Calon F, Kriz J. Accumulation of dietary docosahexaenoic acid in the brain attenuates acute immune response and development of postischemic neuronal damage. Stroke. 2011;42:2903-9.

45. Orr SK, Bazinet RP. The emerging role of docosahexaenoic acid in neuroinflammation. Curr Opin Investig Drugs. 2008;9:735-43. 
46. Wu YQ, Dang RL, Tang MM, Cai HL, Li HD, Liao DH, He X, Cao L, Xue Y, Jiang $P$. Long chain omega-3 polyunsaturated fatty acid supplementation alleviates doxorubicin-induced depressive-like behaviors and neurotoxicity in rats: involvement of oxidative stress and neuroinflammation. Nutrients. 2016:8:243.

47. Lopez-Vales R, Redensek A, Skinner TA, Rathore Kl, Ghasemlou N, Wojewodka G, DeSanctis J, Radzioch D, David S. Fenretinide promotes functional recovery and tissue protection after spinal cord contusion injury in mice. J Neurosci. 2010;30:3220-6.

48. Schober ME, Requena DF, Abdullah OM, Casper TC, Beachy J, Malleske D, Pauly JR. Dietary Docosahexaenoic acid improves cognitive function, tissue sparing, and magnetic resonance imaging indices of Edema and white matter injury in the immature rat after traumatic brain injury. J Neurotrauma. 2016;33:390-402.

49. Wu A, Ying Z, Gomez-Pinilla F. The salutary effects of DHA dietary supplementation on cognition, neuroplasticity, and membrane homeostasis after brain trauma. J Neurotrauma. 2011;28:2113-22.

50. Song C, Li X, Leonard BE, Horrobin DF. Effects of dietary $n-3$ or $n-6$ fatty acids on interleukin-1 beta-induced anxiety, stress, and inflammatory responses in rats. J Lipid Res. 2003;44:1984-91.

51. Kiecolt-Glaser JK, Belury MA, Andridge R, Malarkey WB, Glaser R. Omega-3 supplementation lowers inflammation and anxiety in medical students: a randomized controlled trial. Brain Behav Immun. 2011;25:1725-34.

52. Lotrich FE, Sears B, McNamara RK. Elevated ratio of arachidonic acid to longchain omega-3 fatty acids predicts depression development following interferon-alpha treatment: relationship with interleukin-6. Brain Behav Immun. 2013;31:48-53.

53. Prather AA, Rabinovitz M, Pollock BG, Lotrich FE. Cytokine-induced depression during IFN-alpha treatment: the role of IL-6 and sleep quality. Brain Behav Immun. 2009;23:1109-16.

54. Rapaport MH, Nierenberg AA, Schettler PJ, Kinkead B, Cardoos A, Walker R, Mischoulon D. Inflammation as a predictive biomarker for response to omega-3 fatty acids in major depressive disorder: a proof-of-concept study. Mol Psychiatry. 2016;21:71-9.

55. Harvey LD, Yin Y, Attarwala IY, Begum G, Deng J, Yan HQ, Dixon CE, Sun D. Administration of DHA reduces endoplasmic reticulum stress-associated inflammation and alters Microglial or macrophage activation in traumatic brain injury. ASN Neuro. 2015;7:1-15.

56. Trepanier MO, Kwong KM, Domenichiello AF, Chen CT, Bazinet RP, Burnham WM. Intravenous infusion of docosahexaenoic acid increases serum concentrations in a dose-dependent manner and increases seizure latency in the maximal PTZ model. Epilepsy Behav. 2015;50:71-6.

57. Liu L, Bartke N, Van Daele H, Lawrence P, Qin X, Park HG, Kothapalli K, Windust A, Bindels J, Wang Z, Brenna JT. Higher efficacy of dietary DHA provided as a phospholipid than as a triglyceride for brain DHA accretion in neonatal piglets. J Lipid Res. 2014;55:531-9.

58. Laye S, Gheusi G, Cremona S, Combe C, Kelley K, Dantzer R, Parnet P. Endogenous brain IL-1 mediates LPS-induced anorexia and hypothalamic cytokine expression. Am J Physiol Regul Integr Comp Physiol. 2000;279:R93-8.

59. Lu Y, Zhao LX, Cao DL, Gao YJ. Spinal injection of docosahexaenoic acid attenuates carrageenan-induced inflammatory pain through inhibition of microglia-mediated neuroinflammation in the spinal cord. Neuroscience. 2013;241:22-31.

60. Tremoleda JL, Thau-Zuchman O, Davies M, Foster J, Khan I, Vadivelu KC, Yip PK, Sosabowski J, Trigg W, Michael-Titus AT. In vivo PET imaging of the neuroinflammatory response in rat spinal cord injury using the TSPO tracer [(18)F]GE-180 and effect of docosahexaenoic acid. Eur J Nucl Med Mol Imaging. 2016:43:1710-22.

61. Berressem D, Koch K, Franke N, Klein J, Eckert GP. Intravenous treatment with a long-chain omega-3 lipid emulsion provides neuroprotection in a murine model of ischemic stroke—a pilot study. PLoS One. 2016;11:e0167329.

62. Lu DY, Tsao YY, Leung YM, Su KP. Docosahexaenoic acid suppresses neuroinflammatory responses and induces heme oxygenase- 1 expression in BV-2 microglia: implications of antidepressant effects for omega-3 fatty acids. Neuropsychopharmacology. 2010;35:2238-48.

63. Chang PK, Khatchadourian A, McKinney RA, Maysinger D. Docosahexaenoic acid (DHA): a modulator of microglia activity and dendritic spine morphology. J Neuroinflammation. 2015;12:34.

64. Tremblay ME, Zhang I, Bisht K, Savage JC, Lecours C, Parent M, Titorenko V, Maysinger D. Remodeling of lipid bodies by docosahexaenoic acid in activated microglial cells. J Neuroinflammation. 2016;13:116.
65. Abedin M, Lim J, Tang TB, Park D, Demer LL, Tintut Y. N-3 fatty acids inhibit vascular calcification via the p38-mitogen-activated protein kinase and peroxisome proliferator-activated receptor-gamma pathways. Circ Res. 2006;98:727-9.

66. Wang TM, Hsieh SC, Chen JW, Chiang AN. Docosahexaenoic acid and eicosapentaenoic acid reduce C-reactive protein expression and STAT3 activation in IL-6-treated HepG2 cells. Mol Cell Biochem. 2013;377:97-106.

67. Ji HG, Piao JY, Kim SJ, Kim DH, Lee HN, Na HK, Surh YJ. Docosahexaenoic acid inhibits Helicobacter pylori-induced STAT3 phosphorylation through activation of PPARgamma. Mol Nutr Food Res. 2016;60:1448-57.

68. Xiong H, Du W, Sun TT, Lin YW, Wang JL, Hong J, Fang JY. A positive feedback loop between STAT3 and cyclooxygenase-2 gene may contribute to Helicobacter pylori-associated human gastric tumorigenesis. Int J Cancer. 2014;134:2030-40.

69. Meijerink J, Balvers M, Witkamp R. N-Acyl amines of docosahexaenoic acid and other n-3 polyunsatured fatty acids - from fishy endocannabinoids to potential leads. Br J Pharmacol. 2013;169:772-83.

70. Garbers C, Aparicio-Siegmund S, Rose-John S. The IL-6/gp130/STAT3 signaling axis: recent advances towards specific inhibition. Curr Opin Immunol. 2015;34:75-82

\section{Submit your next manuscript to BioMed Central and we will help you at every step:}

- We accept pre-submission inquiries

- Our selector tool helps you to find the most relevant journal

- We provide round the clock customer support

- Convenient online submission

- Thorough peer review

- Inclusion in PubMed and all major indexing services

- Maximum visibility for your research

Submit your manuscript at www.biomedcentral.com/submit 